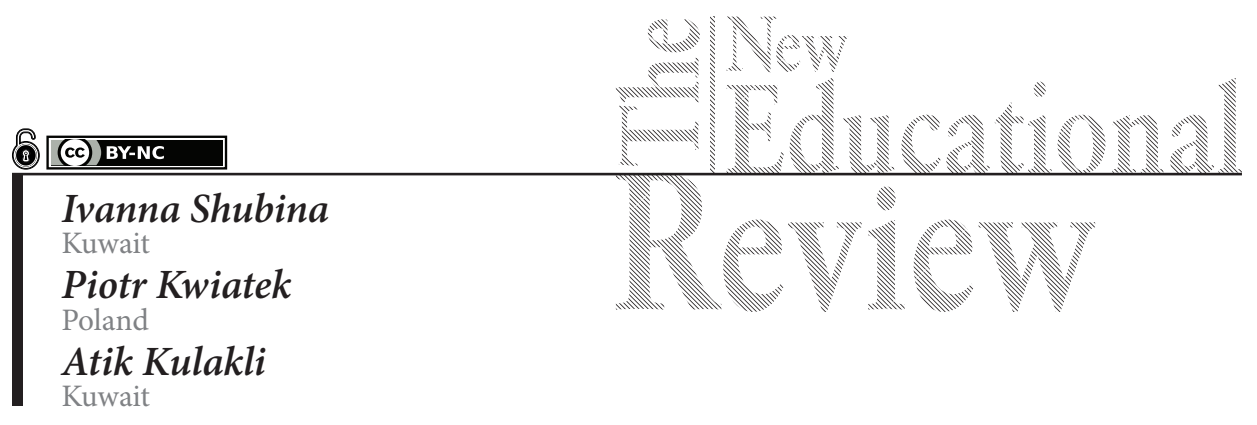

\title{
The Relationships Between Critical Thinking and Creativity Among University Students in Contemporary Education: Empirical Analysis of Gender Differences
}

DOI: 10.15804/tner.2021.65.3.07

\begin{abstract}
Critical and creative thinking skills share a considerable scholarly discussion; little is known about the gender-based differences in students' critical thinking and creativity, along with their impact on academic performance in the Arabian Gulf context. Data for the study were collected through standardized measurements from 220 students and matched with students' performance in various assignments. The data were analyzed through group comparisons and classification algorithms. The results demonstrated gender differences in academic success and relationships between critical thinking and creativity. The current study may assist researchers and practitioners in the educational field who enhance creativity and critical thinking development among students considering gender and academic success. This will allow to improve teaching-learning experiences and prepare youth for their further professional success.
\end{abstract}

Keywords: gender; critical thinking; creative self-efficacy; creative potential; academic success 


\section{Introduction}

As various studies recognized, the creative self-efficacy has a significant impact on creative potential (Shubina \& Kulakli, 2018a; 2018b; Valovičová \& Sollárová, 2020), while the critical thinking skills influence creative abilities (Thayer-Bacon, 2000). The literature on cognitive abilities in education indicates that both critical and creative thinking are essential conditions for purposeful thinking (Paul \& Elder, 2019), which enhances individuals' efficiency in creating novel strategies or products.

The results of previous studies on gender differences in critical and creative thinking are mixed. For example, while Krippner (2010) indicates that gender may determine inhibition of creativity, Torrance (1983) shows that there is no gender difference in tests results. Other studies indicated significant gender differences in critical thinking (Kumar \& James, 2015) and demonstrated differences in the majority of critical thinking subtests with women prevalence (Bart et al., 2015).

Previous studies on the role of creativity and critical thinking in education provide inconclusive results, and there is a need for more in-depth exploration of the relationships between these two types of thinking, and their impact on academic performance. Therefore, we adopted a complementary approach and focus on gender differences among university students and the relationships between their academic success and level of creativity and critical thinking.

\section{Conceptual Framework of the Study}

\section{Relationship between critical and creative thinking and their role in education system}

The potential connections between creative and critical thinking have been studied as a contradictory or complementary. Previous studies indicated that educators tend to focus more on critical thinking development in the learning process (Paul \& Elder, 2019). In addition, fostering critical thinking and enhancing creativity are considered as contradictory in the educational programs and policies (Kulakli \& Mahony, 2014). Recent approach states that creativity involves divergent thinking, suspension of judgment, generating alternatives, imagination, and unconscious processes (Plucker et al., 2004). In addition, the study by Paul \& Elder (2019) showed, that both critical and creative thinking are conditions for purposeful thinking.

Creative self-efficacy as one of the essential self-beliefs is strictly related to students' motivational beliefs and academic ambitions, educator's evaluations of 
creativity expression (Beghetto et al., 2011), creativity evaluations from supervisors (Tierney \& Farmer, 2002), and students' desire to take risks for solving intellectual tasks (Beghetto et al., 2011). Healthy self-efficacy beliefs can help students to perceive a risk as a challenging opportunity (Byrnes, 2013). Although it has been demonstrated that self-efficacy is an essential factor for creativity, the relation between them is not very clear (Shubina \& Kulakli, 2019a).

\section{Gender differences in critical thinking and creativity}

The relationships between gender and both, creative and critical thinking reported in the literature are not clear. For instance, Krippner (2010) finds that gender may determine inhibition of creativity whereas Torrance (1983) argues that there is no gender difference in creative potential. However, there are significant differences between genders in self-perception. The other study argued that creativity and psychological well-being depends on gender (Androshchuk et al., 2020). Females did not perceive themselves as inventors and were strongly influenced by their environment (OECD, 2009). However, a recent study (Kumar \& James, 2015) provides evidence on a higher score in inference and lower in recognition of assumptions among male students.

A study on the relationships between academic majors and gender with measurement of critical thinking disposition stated that females scored higher than males in open-mindedness and maturity scales (Walsh \& Hardy, 1999). Similarly, a study on critical thinking ability (Zetriuslita et al., 2016) indicated the significant gender differences at high-level critical thinking skills, while at moderate or low levels, the differences were not significant. A study conducted by Bart et al. (2015) indicated the occurrence of statistically significant gender differences in the majority of subtests in critical thinking with women prevalence. On the contrary, no significant gender differences were reported for in critical thinking scales of inference and deduction (Bagheri \& Ghanizadah, 2016).

\section{Methodology}

\section{Research Focus}

The present study focuses on the interrelation of critical thinking and creativity concerning academic performance among male and female students. By surveying a reasonable (220 individuals) and diversified (11 majors and various study year levels) sample of students, we aimed to examine the interrelation between critical thinking, creative potential, and creative self-efficacy as well as their impact on 
students' academic success. Specifically, the investigation is carried out into how the creative self-efficacy is related to creative potential and if it influences the academic achievements of students. Our goal is not only to compare the students from different majors and at a different level of study but rather to explore the extent to which the gender may be considered a significant variable differentiating the level of critical thinking and creativity in higher education, as well as relationships between them.

\section{Instrument and Procedures}

The data collected for this study included students' creative potential, critical thinking, and self-evaluation of creativity. Also, students' course records were obtained to calculate the grades from two types of assessments: 1 . Requiring students to think critically (exam-like assessments); 2 . Requiring creative thinking assessments.

Previously used and validated scales were used to collect the data. The creative potential was measured through Kincher's creative potential scale (Iljin, 2012). Critical thinking was measured through the Watson-Glaser Critical Thinking Appraisal tool (Watson \& Glaser, 2002), and creativeness was measured using a questionnaire for creative self-esteem (Iljn, 2012).

\section{Results of Research}

\section{Data, Psychometric Properties and Common Method Variance}

The data obtained from students' self-evaluations were coded into SPSS 24 and merged with students' records on assignments. In total, data on 220 students were collected. The sample consisted of 86 female and 134 male students. When it comes to students' performance, we discern between two different types of assessments: (1) creativity-based assessments (CAG), and critical thinking assessments (EAG) (Table 1).

Table 1. Descriptive Statistics

\begin{tabular}{|c|c|c|c|c|}
\hline Variables & Group & M & $\mathrm{Me}$ & SD \\
\hline \multirow[t]{2}{*}{$\mathrm{CT}$} & Female & 9.72 & 9.0 & 2.44 \\
\hline & Male & 8.40 & 8.0 & 2.04 \\
\hline \multirow[t]{2}{*}{ CSE } & Female & 9.86 & 10.0 & 1.53 \\
\hline & Male & 8.78 & 9.0 & 2.04 \\
\hline
\end{tabular}




\begin{tabular}{llcccc}
\hline \multicolumn{1}{c}{ Variables } & & Group & M & Me & SD \\
\hline CP & Female & 24.42 & 24.0 & 9.63 \\
\hline & Male & 27.61 & 26.0 & 12.64 \\
\hline CAG & Female & 90.32 & 92.33 & 6.64 \\
\hline & Male & 90.34 & 91.83 & 5.38 \\
\hline EAG & Female & 56.84 & 56.0 & 14.94 \\
\hline & Male & 58.69 & 60.0 & 16.94 \\
\hline
\end{tabular}

Note: $\mathrm{M}=$ Mean; $\mathrm{Me}=$ Median; $\mathrm{SD}=$ Standard Deviation; $\mathrm{CT}=$ Critical Thinking; $\mathrm{CSE}=$ Creative Self-Efficacy; $\mathrm{CP}=$ Creative Potential; $\mathrm{CAG}=$ Creative Assessments Grade; $\mathrm{EAG}=$ Examination Assessments Grade.

Table 2 provides correlation coefficients for the total sample as well as for the gender-split. In the total sample, only students' results (creative tasks and exams) show moderate correlation $(\mathrm{r}=.61, \mathrm{p}<0.01)$, while CSE is marginally correlated with $\mathrm{CP}(\mathrm{r}=.17, \mathrm{p}<0.05)$. However, the analysis of gender-split correlation points to differences in the patterns. CSE is correlated with CP in the male subsample $(\mathrm{r}=.29, \mathrm{p}<0.01)$ but not in the female subsample $(\mathrm{r}=.04, \mathrm{p}>0.05)$. Likewise, CSE correlates negatively with CT in the male subsample $(\mathrm{r}=-.19, \mathrm{p}<0.05)$ but not in the female one $(\mathrm{r}=.19, \mathrm{p}>0.05)$. In other words, creative self-efficacy and creative potential are positively related in case of male students. In case of female students, we observe that creative potential is positively related to critical thinking.

Table 2. Correlations

\begin{tabular}{|c|c|c|c|c|}
\hline Variables & 1 & 2 & 3 & 4 \\
\hline \multicolumn{5}{|c|}{ Total Sample } \\
\hline \multicolumn{5}{|l|}{ 1. CAG } \\
\hline 2. EAG & $.61^{\star *}$ & & & \\
\hline 3. CP & -.11 & -.07 & & \\
\hline 4. CT & -.04 & .01 & -.06 & \\
\hline 5. CSE & -.01 & .03 & $.17^{\star}$ & -.09 \\
\hline \multicolumn{5}{|c|}{ Male } \\
\hline \multicolumn{5}{|l|}{ 1. CAG } \\
\hline 2.EAG & $.62^{\star *}$ & & & \\
\hline 3. $\mathrm{CP}$ & -.15 & -.11 & & \\
\hline 4. CT & -.17 & -.05 & $-.18^{\star}$ & \\
\hline 5. CSE & .01 & .04 & $.29^{* *}$ & $-.19^{\star}$ \\
\hline
\end{tabular}




\begin{tabular}{lcccc}
\hline \multicolumn{1}{c}{ Variables } & 1 & 2 & 3 & 4 \\
\hline \multicolumn{5}{c}{ Female } \\
\hline 1. CAG & \multicolumn{5}{c}{. } & & & \\
\hline 2. EAG & $.61^{\star \star}$ & & & \\
\hline 3. CP & -.05 & -.09 & $.25^{\star}$ & \\
\hline 4. CT & .09 & .15 & .04 & -.19 \\
\hline 5. CSE & -.05 & .08 & 08 \\
\hline
\end{tabular}

Note: $\mathrm{CT}=$ Critical Thinking; $\mathrm{CSE}=$ Creative Self-Efficacy; $\mathrm{CP}=$ Creative Potential; $\mathrm{CAG}=$ Creative Assessments Grade; EAG=Examination Assessments Grade; ${ }^{* *} \mathrm{p}<0.01,{ }^{*} \mathrm{p}<0.05$.

Different pattern of correlations suggests that underlying differences may exist between both genders. We continue the discussion by a more detailed comparison between genders.

\section{Analysis and results}

The Kolmogorov-Smirnoff test performed on CT and CSE yielded significant results $(\mathrm{p}<0.01)$, while the normality assumption was not violated for $\mathrm{CP}$. Thus, the potential differences between genders in the levels of CT and CSE were evaluated with a non-parametric Mann-Whitney test, and CP differences were assessed with a t-test.

We found a significant effect of gender for both $\mathrm{CT}(\mathrm{U}=3.82, \mathrm{Z}=-4.27, \mathrm{p}<0.01$, $\mathrm{r}=.29)$ and $\operatorname{CSE}(\mathrm{U}=3.85, \mathrm{Z}=-4.23, \mathrm{p}<0.01, \mathrm{r}=.28)$ scores(the effect size was calculated by dividing the absolute standardized test statistic by the square root of pairs compared).Female students show higher critical thinking scores (MCTS $\mid \mathrm{F}=9.0$ ) and creative self-efficacy (MCSE $\mid \mathrm{F}=10.0)$ than male students (MCTS $\mid \mathrm{M}=8.0$ and MCSE $\mid M=9.0$ respectively). Although researchers reported no significant differences between males and females, the stated gender-based creativity differences might be influenced by the intense modernization in the country and increase in gender equality.

An independent sample t-test was conducted to compare the creative potential between female and male students. There was a significant difference in score between the two groups, $\mathrm{t}(218)=-2.00, \mathrm{p}=.47$, with male students scoring higher $(M=27.61, S D=12.64)$ than female students $(M=24.42, S D=9.63)$. The magnitude of the differences in the means (mean difference $=-3.19,95 \% \mathrm{CI}$ : -6.34 to -.05$)$ was small $\left(\eta^{2}=.05\right)$. Gender differences certainly exist, but these are not global or generalizable across domains. For instance, more men than women are creative in invention domain, especially in mechanical and scientific areas (Kaufman 2006). 
We employed one-way ANOVA to compare means of examination-like and creative-like assessments of students. The results yielded no significant gender differences, neither for examination-like assessments $(\mathrm{F}(218)=.680, \mathrm{p}=.41)$ nor for creative-like assessments $(\mathrm{F}(218)=.001, \mathrm{p}=.98)$. To further investigate the differences in performance between the genders, we proceed with analyzing more fine-grained clusters. We used a K-means procedure with the Euclidean distance to identify groups of students with a similar combination of results (examination-like versus creative-like). The clustering procedure demands the number of clusters to be provided a'priori. A scree plot pointed to a 3-cluster solution.

Table 3. Clusters of Students' Performances

\begin{tabular}{lrcc}
\hline & \multicolumn{3}{c}{ Cluster } \\
\hline Cluster name & LowC-LowE & HighC-LowE & HighC-HighE \\
\hline CAG & 85.69 & 89.93 & 94.47 \\
\hline EAG & 38.40 & 56.80 & 74.90 \\
\hline $\mathrm{n}$ & 66 & 73 & 81 \\
\hline
\end{tabular}

Note: $\mathrm{CAG}=$ Creative Assessment Grade; $\mathrm{EAG}=$ Examination Assessment Grade.

The resulting clusters were named regarding the median value of creative and examination results respectively ("Low" for values below the median and "High" for values above the median. The centers and sizes of each cluster are provided in the Table 3.

As depicted in Figure 1, the patterns of students' performance (grades) do differ between genders, especially in high achievement clusters (i.e., HighC-HighE). More specifically, female students are more likely to score higher in creative assignments and lower in exams (females: $36.05 \%$, males: $31.34 \%$ ), while male students, in part, score high in both types of assessments (females: $33.72 \%$, males: $38.81 \%$ ). We note, that though the results between male and female students do differ, gender alone is related more to a type of assessment than its level.

To further confirm the differences, we subjected the data on students' self-evaluations and the cluster classification to logistic regression with student's gender as the dependent variable. We used the cluster membership as a control variable because of different correlation patterns (Table 2).

The Hosmer-Lemeshow goodness-of-fit test yielded a $\chi^{2}$ of $12.131(\mathrm{p}>0.05)$, suggesting that the model fits the data well. The accuracy of gender prediction based on the proposed model was better than by chance ( 80.8 percent). 

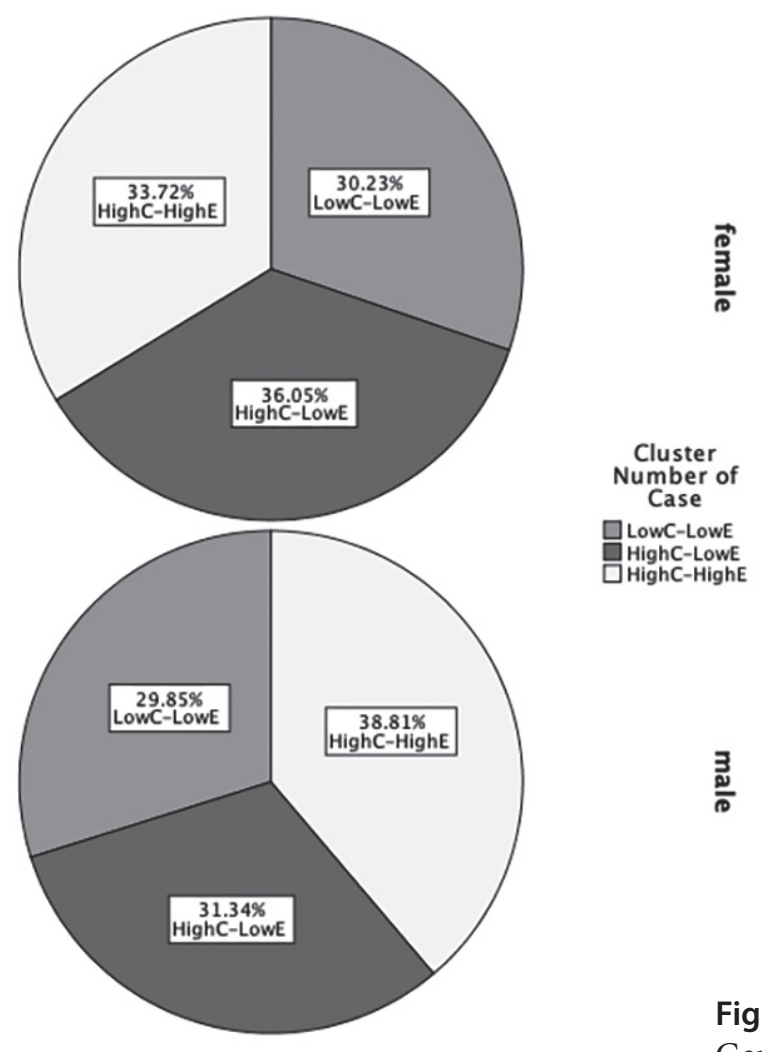

Figure 1. Cluster Classification by Gender

Table 4. Results of Logistic Regression

\begin{tabular}{lllll}
\hline & $\beta$ & SE & Wald & $\operatorname{Exp}(\beta)$ \\
\hline Cluster & .189 n.s. & .193 & .958 & 1.208 \\
\hline CP & $.041^{* *}$ & .015 & 7.268 & 1.042 \\
\hline CSE & $-.447^{* *}$ & .095 & 22.306 & .640 \\
\hline CT & $-.331^{* *}$ & .075 & 19.651 & .719 \\
\hline
\end{tabular}

Note: $\mathrm{df}=1 ; \mathrm{M}=$ Mean; Cluster $=$; $\mathrm{CT}=$ Critical Thinking; $\mathrm{CSE}=$ Creative Self-Efficacy; $\mathrm{CP}=$ Creative Potential; n.s. $=$ not significant. ${ }^{* *} p<0.05$ (two-tailed). Constant was omitted.

Higher CP $(b=.04, \mathrm{p}<0.05)$ increases chances to identify a subject student as a male by $4.2 \%$. Interestingly, the log of odds for a student to be identified as a female was negatively related to CSE $(\mathrm{p}<0.05)$ and CT $(\mathrm{p}<0.05)$. 
In summary, we confirm the gender differences using two different means of comparison. We find that there are significant gender differences in critical thinking, creative potential and creative self-efficacy, however, it is naïve to suggest either that one gender is more efficient in mentioned abilities than another, or that there are no differences between them. The relationship between measured variables appears to be far more complex.

\section{Discussion}

One of the essential goals of a contemporary educational system is to prepare the students for their further professional success by providing appropriate opportunities for students' cognitive skills development, including creative and critical thinking. It is also important to examine how gender can influence the preparation and the structuring of the course, as well as applied in practice teaching strategies. This study is one of the first attempts to explore the relationships between all three variables simultaneously.

The findings provide gender differences in the critical thinking and creativity of students, along with their impact on academic performance. The results emphasize the essential role of both critical and creative thinking for individual success in academic and consequently, professional life. However, some of the studies analyzed the impact of self-efficacy on creativity, this study is one of the first attempts to explore this and other related variables empirically.

The study provided evidence for essential gender differences in critical thinking, creativity and the relationships between them. More precisely, significant gender-based differences were identified in four dependent variables, namely critical thinking, creative potential, creative self-efficacy, and academic success. These are important insights into gender-based relationships between creative and critical thinking concerning the Arabian Gulf context.

Female student's scored higher in respective tests in critical thinking and creative self-efficacy than their male peers. Contrary to our expectations, male students scored higher in creative potential tests. A potential explanation of the differences is a cultural context.

The correlation patterns showed a significant, yet small relationship between creative self-efficacy and creative potential (Table 2). The analysis of gender-split correlations among creative potential, creative self-efficacy and critical thinking for male students are negative. On the contrary, the positive correlation between 
creative potential and critical thinking was observed for female students, while other correlations were not significant.

Despite the differences being small, female students tend to score higher in creative assessments, while male students tend to score higher in assessments like exams. Consequently, the results of the current study are coherent with the results of the study by Kumar and James (2015), indicating gender differences in critical thinking with the prevalence of male students in inference scale. This factor can be considered as one of the reasons why male students scored higher in exam-like assessments.

The results of the logistic regression show that based on the level of skills, student's gender can be identified. To our knowledge, this is the first study in a current literature review, which aims to discover the possibilities of identifying the gender based on demonstrated cognitive skills.

\section{Limitations of the study and Future Directions}

The findings discussed in this study have some limitations. The sample included in this study is representative for the students in Kuwait and the results cannot be generalized to all students from the Middle East. The measures we used in the study, although comprehensive, may influence participants' answers to "fit" to existing categories or patterns, which may hamper their expression of personal beliefs and opinions.

Future research can examine how gender differences vary even more in various social and educational environments. Further, it would also be valuable to see how the self-beliefs of students and teachers are related to the level of creativity and critical thinking, and quality of the relationship between critical thinking and creativity.

\section{Acknowledgements}

We would like to express our thanks to all the students who participated in this study.

\section{References}

Androshchuk, I., Balakhtar, V., Balakhtar, K., \& Oleshko, P. (2020). Creativity as a Factor in the Psychological Well-Being of Teachers of Higher Educational Institutions. The New Educational Review, 60, 191-202.191. doi: 10.15804/tner.2020.60.2.15.

Bagheri, F., \& Ghanizadeh, A. (2016). Critical thinking and gender differences in aca- 
demic self-regulation in higher education. Journal of Applied Linguistics and Language Research, 3 (3), 133-145.

Bart, W.M., Hokanson, B., Sahin, I., \& Abdelsamea, M.A. (2015). An investigation of the gender differences in creative thinking abilities among $8^{\text {th }}$ and $11^{\text {th }}$ grade students. Thinking Skills and Creativity, 17, 17-24. doi: 10.1016/j.tsc.2015.03.003.

Beghetto, R.A., Kaufman, J.C., \& Baxter, J. (2011). Answering the unexpected questions: Exploring the relationship between students' creative self-efficacy and teacher ratings of creativity. Psychology of Aesthetics, Creativity, and the Arts, 5 (4), 342-349.doi: 10.1037/ a0022834.

Byrnes, J.P. (2013). The nature and development of decision-making: A self-regulation model. New York: Psychology Press.

Gray, A. (2016, January). The 10 skills you need to thrive in the Fourth Industrial Revolution. In World Economic Forum, 19. Retrieved 3/10/201, from https://www.weforum.org/ agenda/2016/01/the-10-skills-you-need-to-thrive-in-the-fourth-industrial-revolution

Iljin, E.P. (2012). Psychology of creativity, imagination, and giftedness. SpВ: Piter. // Ильин, Е.П. (2012). Психология творчества, креативности, одаренности. СПб: Питер.

Kaufman, J.C. (2006). Self-reported differences in creativity by ethnicity and gender. Applied Cognitive Psychology, 20(8), 1065-1082. doi: 10.1002/acp.1255.

Krippner, S. (2010). The social construction of creative children. In A. Hussain \& N. Idris (Eds.), Dimensions of education, 157-166. New Delhi, India: Gyan Publishing House.

Kulakli, A., \& Mahony, S. (2014). Knowledge creation and sharing with Web 2.0 tools for teaching and learning roles in so-called University 2.0. Procedia-Social and Behavioral Sciences, 150, 648-657.

Kumar, R., \& James, R. (2015). Evaluation of critical thinking in higher education in Oman. International Journal of Higher Education, 4 (3), 33-43. doi:10.5430/ijhe.v4n3p33.

OECD (Organisation for Economic Cooperation and Development). (2009). PISA 2009: Assessment Framework. Programme for the International Students Assessment, Retrieved 5/10/201, from https://www.oecd.org/pisa/pisaproducts/44455820.pdf

Paul, R., \& Elder, L. (2019). The nature and functions of critical \& creative thinking. New York: Rowman \& Littlefield.

Plucker, J.A., Beghetto, R.A., \& Dow, G.T. (2004). Why isn't creativity more important to educational psychologists? Potentials, pitfalls, and future directions in creativity research. Educational psychologist, 39 (2), 83-96. doi: 10.1207/s15326985ep3902_1.

Podsakoff, P.M., MacKenzie, S.B., Lee, J.Y., \& Podsakoff, N.P. (2003). Common method biases in behavioral research: a critical review of the literature and recommended remedies. Journal of applied psychology, 88 (5), 879-903. doi: 10.1037/0021-9010.88.5.879.

Shubina, I., \& Kulakli, A. (2018a). Critical Thinking in Relation with Educational Technologies. Proceedings of ERPA International Congress on Education, Istanbul, Turkey, June, 685-692.

Shubina, I., \& Kulakli, A. (2018b). From creative abilities to creative personality: contemporary debates. International Scientific-Practical Conference Economics, Finance and 
Management in the 21. Century: Analysis of Trends and Development Prospect, 21 (1), 86-90.

Shubina, I., \& Kulakli, A. (2019). Pervasive learning and technology usage for creativity development in education. International Journal of Emerging Technologies in Learning (iJET), 14 (01), 95-109.

Shubina, I., \& Kulakli, A. (2019). Critical Thinking, Creativity and Gender Differences for Knowledge Generation in Education. Literacy Information and Computer Education Journal (LICEJ), 10 (1), 3086-3093.

Thayer-Bacon, B.J. (2000). Transforming critical thinking: Thinking constructively. New York: Teachers College Press.

Tierney, P., \& Farmer, S.M. (2002). Creative self-efficacy: Its potential antecedents and relationship to creative performance. Academy of Management journal, 45 (6), 1137-1148. doi: $10.2307 / 3069429$.

Torrance, E.P. (1983). Status of creative women: Past, present, and future. Creative Child and Adult Quarterly, 8 (3), 135-144. doi: 10.2307/24398588.

Zetriuslita, H., Ariawan, R., \& Nufus, H. (2016). Students' Critical Thinking Ability: Description Based on Academic Level and Gender. Journal of Education and Practice, 7(12), 154-164. https://files.eric.ed.gov/fulltext/EJ1099476.pdf

Valovičová, L. \& Sollárová, E. (2020). Effects of an Empirical Cognition Development Programme on the Creative Thinking of Preschool Children. The New Educational Review, 60, 85-95. doi: 10.15804/tner.2020.60.2.07.

Walsh, C.M., \& Hardy, R.C. (1999). Dispositional differences in critical thinking related to gender and academic major. Journal of Nursing Education, 38 (4), 149-155.

Watson, G., \& Glaser, E. (2002). Watson-Glaser critical thinking appraisal, UK edition: practice test. London: Pearson.

Advised by Sarp Erkir, Associate Professor,

Head of Liberal Arts Department, American University of the Middle East, Kuwait

Advised by Vikinta Rosinaite, Associate Professor,

Research Coordinator, American University of the Middle East, Kuwait 